\title{
Cold-induced vasoconstriction at forearm and hand skin sites: the effect of age
}

\author{
B. R. M. Kingma • A. J. H. Frijns • W. H. M. Saris • \\ A. A. van Steenhoven - W. D. van Marken Lichtenbelt
}

Accepted: 18 February 2010 / Published online: 19 March 2010

(C) The Author(s) 2010. This article is published with open access at Springerlink.com

\begin{abstract}
During mild cold exposure, elderly are at risk of hypothermia. In humans, glabrous skin at the hands is well adapted as a heat exchanger. Evidence exists that elderly show equal vasoconstriction due to local cooling at the ventral forearm, yet no age effects on vasoconstriction at hand skin have been studied. Here, we tested the hypotheses that at hand sites (a) elderly show equal vasoconstriction due to local cooling and (b) elderly show reduced response to noradrenergic stimuli. Skin perfusion and mean arterial pressure were measured in 16 young adults (Y: 18-28 years) and 16 elderly (E: 68-78 years). To study the effect of local vasoconstriction mechanisms local sympathetic nerve terminals were blocked by bretylium (BR). Baseline local skin temperature was clamped at $33^{\circ} \mathrm{C}$. Next, local temperature was reduced to $24^{\circ} \mathrm{C}$. After $15 \mathrm{~min}$ of local cooling, noradrenalin (NA) was administered to study the effect of neural vasoconstriction mechanisms. No significant age effect was observed in vasoconstriction due to local cooling at BR sites. After NA, vasoconstriction at the forearm showed a significant age effect; however, no significant age effect was found at the hand sites. [Change in CVC (\% from baseline): Forearm Y: $-76 \pm 3$ vs. E: $-60 \pm 5(P<0.01)$,
\end{abstract}

Communicated by Narihiko Kondo.

B. R. M. Kingma $(\bowtie) \cdot$ W. H. M. Saris ·

W. D. van Marken Lichtenbelt

Department of Human Biology, NUTRIM School for Nutrition,

Toxicology and Metabolism of Maastricht Universitary

Medical Centre+, Universiteitssingel 50,

6200 MD Maastricht, The Netherlands

e-mail: B.Kingma@HB.unimaas.nl

A. J. H. Frijns · A. A. van Steenhoven

Department of Mechanical Engineering,

Eindhoven University of Technology,

Eindhoven, The Netherlands dorsal hand Y: $-74 \pm 4$ vs. E: $-72 \pm 4$ (n.s.), ventral hand Y: $-80 \pm 7$ vs. $\mathrm{E}:-70 \pm 11$ (n.s.)]. In conclusion, in contrast to results from the ventral forearm, elderly did not show a blunted response to local cooling and noradrenalin at hand skin sites. This indicates that at hand skin the noradrenergic mechanism of vasoconstriction is maintained with age.

Keywords Thermoregulation · Aging · Glabrous skin

\section{Introduction}

With advancing age, thermoregulatory defense mechanisms may be impaired. Recent studies indicate that even during mild cold exposure elderly are predisposed to risk of hypothermia (DeGroot and Kenney 2007). Skin blood flow is a major effector of heat loss in humans, as it transports heat from the body core to the skin. DeGroot and Kenney (2007) report a reduced vasoconstrictor response in elderly subjects compared with young adults. However, their biophysical analysis could not explain why elderly failed to defend their core temperature. In his editorial response van Someren proposed (Van Someren 2007) that there might be an underestimation in calculations of the actual heat loss, because the regions rich in arterio venous anastomoses (AVA) are generally not taken into account. AVAs are predominantly found in glabrous skin such as palms, fingers, soles, and forehead (Bergersen et al. 1997; Donadio et al. 2006; Gorgas et al. 1977; Lenasi and Strucl 2004). Together with their relatively large surface to volume ratio and high sensitivity to thermal changes (Defrin et al. 2009), these locations are ideally adapted as heat exchangers with the environment (Grahn and Craig Heller 2004; Grahn et al. 2009; Van Someren 2007). Hence, a blunted perfusion response in elderly in these skin areas might explain why 
elderly fail to maintain their core temperature when exposed to cold (Gilbert et al. 1999). Clothing provides insulative protection to most of the body surface. Therefore, the initial defense to cold might be related to local cooling of exposed areas, which in fact are mainly glabrous skin sites (forehead and hands). Age effects on mechanisms of mediating local cold-induced vasoconstriction are well documented for non-glabrous human forearm skin, yet no information is available for glabrous (hand) skin.

Neurally mediated vasoconstriction works primarily through sympathetic adrenergic axon reflexes and alpha $2_{2}$ adrenergic receptors (Hodges et al. 2007; Kellogg 2006; Pergola et al. 1993). However, in vitro research does not support findings of increased cold-related axonal release of sympathetic adrenergic agents (Johnson 2007). Therefore, non-neural mechanisms are likely involved. Non-neural mechanisms include the rho-kinase pathway and removal of nitric oxide (Hodges et al. 2006; Thompson-Torgerson et al. 2007a). Experimental evidence indicates that the early phase of vasoconstriction due to local cooling is mainly dependent on neural regulation and that late phase vasoconstriction relies more on non-neural mechanisms (Pergola et al. 1993).

From literature it is known that during local cooling, young adults and elderly show a similar level of vasoconstriction at the ventral forearm (Thompson et al. 2005a; Thompson-Torgerson et al. 2007b). Interestingly, the actual mechanisms by which the vasoconstriction is mediated are different. Elderly show a reduced response to noradrenergic agents (Thompson et al. 2005a), yet this is compensated by an increased vasoconstriction through non-adrenergic mechanisms (Thompson-Torgerson et al. 2007b). It is unclear whether young and elderly show different vasoconstriction due to local cooling at other skin sites than the forearm, such as glabrous and non-glabrous skin of the hand. Many studies describe that innervation and topology of cutaneous microcirculation are not homogenous (Donadio et al. 2006; Johnson et al. 1995; Kellogg 2006; Krogstad et al. 1995; Wilson et al. 2005; Yamazaki and Sone 2006). For instance, glabrous skin (palms, fingers, soles, lips) is innervated mostly by sympathetic noradrenergic nerves and is rich in AVAs (Alvarez et al. 2006; Charkoudian 2003; Donadio et al. 2006; Kellogg 2006; Krogstad et al. 1995). Studies by Ekenvall et al. have shown that vascular responses to local cooling and noradrenalin in human finger skin (glabrous) are primarily mediated through alpha $2^{-}$ adrenergic receptors (Ekenvall et al. 1988; Lindblad et al. 1990). In contrast to glabrous skin, non-glabrous skin has no AVAs and is innervated by both noradrenergic and cholinergic nerves (Kellogg 2006).

In this study, we are interested in age-related differences in perfusion in response to cooling at the hand sites. No data on age effects on vasoconstriction due to local cooling at hand skin and mechanisms that mediate it are available in literature. Therefore, we tested the hypotheses that at hand sites (a) elderly show equal vasoconstriction due to local cooling and (b) elderly show reduced perfusion response to neuronal (nor-adrenergic) stimuli.

\section{Methods}

Ethical approval

The medical ethical committee of Maastricht University Medical Center + approved the study. Each subject gave verbal and written informed consent prior to participation in the study. All procedures conformed to the standards of the Declaration of Helsinki.

\section{Subjects}

Sixteen young adults $(18-28$ years; $8 \mathrm{M}, 8 \mathrm{~F})$ and sixteen elderly (68-78 years, $8 \mathrm{M}$, $8 \mathrm{~F}$ ) were included (characteristics in Table 1). All subjects were healthy, non-obese, nonsmokers, and not taking medications. All young females were tested during the early follicular phase of their menstrual cycle. Subjects refrained from caffeinated or alcoholic beverages in the morning prior to the test, but were allowed to eat a small breakfast.

\section{Protocol}

Because of increased sympathetic vascular tone in the morning (Panza et al. 1991) experiments were conducted in the afternoon. After subjects were seated skin sites were cleaned with alcohol and air-dried. The studied skin sites were the dorsal side of the hand between the 2nd and 3rd

Table 1 Selected subject characteristics

\begin{tabular}{llll}
\hline Subject characteristics & $\mathrm{Y}(n=16)$ & $\mathrm{E}(n=16)$ & $P$ value \\
\hline Age (year) & $23.19 \pm 0.73$ & $71.33 \pm 0.61^{*}$ & $P<0.01$ \\
Gender (Male/female) & $8 / 8$ & $8 / 8$ & \\
Height (m) & $1.74 \pm 0.02$ & $1.67 \pm 0.02^{*}$ & $P<0.04$ \\
Mass $(\mathrm{kg})$ & $64.36 \pm 2.32$ & $65.77 \pm 2.29$ & N.S. \\
BMI $\left(\mathrm{kg} / \mathrm{m}^{2}\right)$ & $21.25 \pm 0.73$ & $23.42 \pm 0.53^{*}$ & $P<0.01$ \\
Systolic BP $(\mathrm{mmHg})$ & $119.00 \pm 2.69$ & $129.47 \pm 3.63^{*}$ & $P<0.03$ \\
Diastolic BP $(\mathrm{mmHg})$ & $66.38 \pm 1.17$ & $69.07 \pm 2.28$ & N.S. \\
Mean BP $(\mathrm{mmHg})$ & $83.92 \pm 1.24$ & $89.20 \pm 2.12^{*}$ & $P<0.04$ \\
Mean skin temp. $\left({ }^{\circ} \mathrm{C}\right)$ & $33.74 \pm 0.04$ & $32.9^{\circ} \mathrm{C} \pm 0.06^{*}$ & $\mathrm{P}<0.01$ \\
Whole body fat $(\%)$ & $22.48 \pm 2.00$ & $27.40 \pm 1.81$ & N.S. \\
Leisure activity level & $3.31 \pm 0.12$ & $3.55 \pm 0.11$ & N.S. \\
\hline
\end{tabular}

Values are presented as mean \pm SEM

$Y$ young adults, $E$ elderly, $B P$ blood pressure

$* P<0.05$ versus young adult 
metacarpal, the ventral hand at the base of the thumb, and the ventral forearm halfway the wrist and inner side of the elbow. To reduce the influence of age differences in systemic sympathetic adrenergic tone (Wilson et al. 2004) bretylium tosylate $(10 \mathrm{mM}$, Bio-Connect, the Netherlands), diluted in glycol propylene, was delivered via iontophoresis (PerIont, Sweden). Iontophoresis is a non-invasive method of delivering a drug through the skin using a small electric charge. Bretylium (BR) is a positively charged drug, which is propelled through the cutaneous barrier by the anode of the iontophoretic chamber. Glycol propylene was chosen as a carrier as it is non-conducting by itself; hence it does not interfere with the drug delivery (Kellogg et al. 1989). Bretylium is known to selectively block local endogenous release of noradrenergic neurotransmitters (Kellogg et al. 1989). Because of inherent differences in skin permeability between glabrous and non-glabrous skin, iontophoretic characteristics were modified between sites to deliver a dose that caused a similar physiologic effect. Aging per se may affect the cutaneous barrier properties (Carmeli et al. 2003). Thus, the iontophoresis dose scheme was set at a level to be maximally effective for both groups. From literature (Johnson et al. 1995; Kellogg et al. 1989; Pergola et al. 1993; Yamazaki and Sone 2006) and a pilot study it was concluded that for effective bretylium treatment, different duration and current strength of iontophoresis was needed for different sites, as shown in Table 2. Control measurements (BR-) of perfusion response to local cooling were performed ipsilateral to the locations treated with bretylium (BR+). After iontophoresis of bretylium, sites were given $1 \mathrm{~h}$ for hyperemia to subside and sympathetic blocking to take effect. Skin temperature was measured in 1 min intervals using iButtons (type DS1921H; Maxim/ Dallas Semiconductor Corp., USA) (van Marken Lichtenbelt et al. 2006) at the 14 positions of the adapted Mitchel/ Wyndham equation for mean skin temperature (Choi et al. 1997). Next, subjects were dressed in a water-perfused suit (TUBEsuit, DTI) to control whole body skin temperature

Table 2 Current and duration of iontophoresis $\left(0.5 \mathrm{~cm}^{2}\right)$ and concentration of drugs at treated skin sites

\begin{tabular}{llll}
\hline $\begin{array}{l}\text { Iontophoresis properties } \\
\text { at treated skin sites }\end{array}$ & $\begin{array}{l}\text { Current } \\
(\mathrm{mA})\end{array}$ & $t$ (min) & $\begin{array}{l}\text { Concentration } \\
(\mathrm{mM})\end{array}$ \\
\hline $\begin{array}{l}\text { Bretylium } \\
\quad \text { Dorsal hand }\end{array}$ & 0.24 & 15 & 10 \\
$\quad$ Ventral hand & 0.30 & 25 & 10 \\
$\quad$ Ventral forearm & 0.24 & 10 & 10 \\
$\quad$ Noradrenalin & & & \\
$\quad$ Dorsal hand & 0.24 & 1 & 2.5 \\
$\quad$ Ventral hand & 0.30 & 5 & 5.0 \\
$\quad$ Ventral forearm & 0.24 & 1 & 2.5 \\
\hline
\end{tabular}

(Blanketrol II, Cincinnati Sub-zero). The effectiveness of the bretylium treatment was tested via whole body cooling by setting the temperature of the water perfused suit to $26^{\circ} \mathrm{C}$. Whole body cooling elicits reflex vasoconstriction through release of noradrenalin and cotransmitters from sympathetic nerve terminals; effective blockade of presynaptic nerve terminals abolishes the response, while at nontreated sites perfusion drops (Kellogg et al. 1989). During the rest of the experiment, subjects remained in thermal comfort by perfusing the suit with water at $33^{\circ} \mathrm{C}$ (Parsons 2003). Room temperature was kept at $24^{\circ} \mathrm{C}$. Laser Doppler flowmetry (Perimed PF5000, Sweden) was used for measurement of skin perfusion. Custom-made Peltier elements in the casing of the probes allowed for local temperature control of skin sites at $24^{\circ} \mathrm{C}$ and $33^{\circ} \mathrm{C}$. Measurements were divided into three phases (see Fig. 1). After a $30 \mathrm{~min}$ baseline period at $33^{\circ} \mathrm{C}$, skin sites were cooled to $24^{\circ} \mathrm{C}\left(5^{\circ} \mathrm{C} /\right.$ $\mathrm{min}$ ) for $15 \mathrm{~min}$, until perfusion reached a nadir. Next noradrenalin, diluted in glycol propylene (Bio-Connect, the Netherlands), was delivered transcutaneously via iontophoresis to simulate maximal response to noradrenergic stimulation (details in Table 2, example recording in Fig. 2).

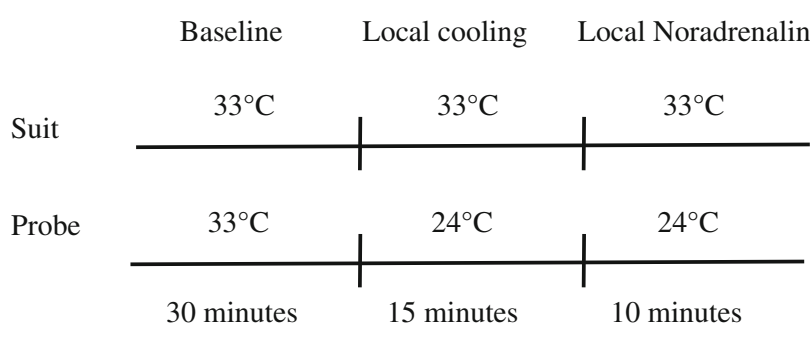

Fig. 1 Timeline of measure protocol repeated at each skin site. Blood pressure was measured at start of baseline and at end of noradrenalin phase

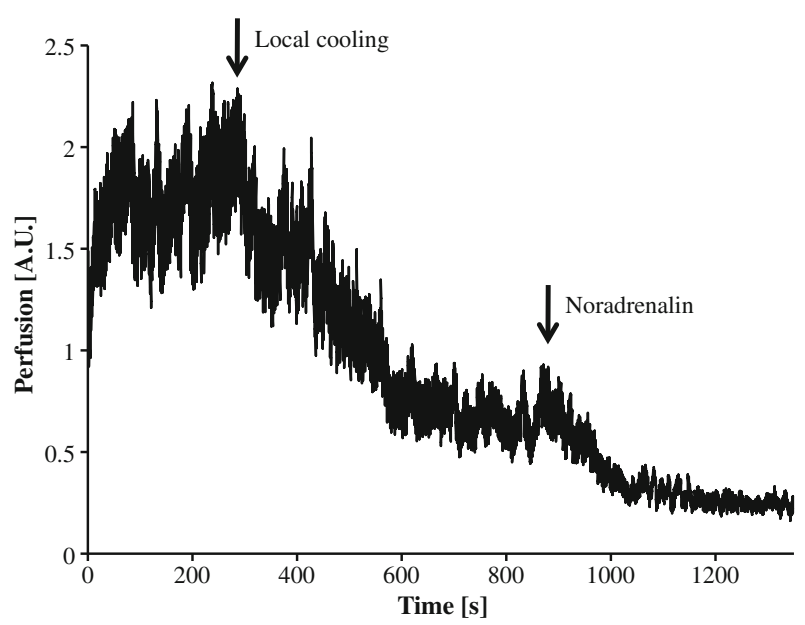

Fig. 2 Individual recording of skin perfusion. Local skin temperature was $33^{\circ} \mathrm{C}$ during baseline, $24^{\circ} \mathrm{C}$ during cooling and administration of noradrenalin 
At control sites $(\mathrm{BR}-)$ noradrenalin was delivered to a subset of subjects only (young: $n=11$ and elderly: $n=13$ ).

A study by Thompson (Thompson et al. 2005a) has shown that local cooling of skin and local administration of NA does not alter mean arterial pressure (MAP). Therefore, and to minimize the influence of the blood pressure (BP) measurement itself to the perfusion, BP measurement was restricted to before baseline and after administration of noradrenalin via digital blood pressure monitoring (CRESTA, Taiwan). Cutaneous vascular conductance (CVC) was calculated as perfusion divided by mean arterial pressure $(\mathrm{MAP}=1 / 3$ systolic $\mathrm{BP}+2 / 3$ diastolic $\mathrm{BP})$. Whole body fat percentage was measured through Dual-X-ray Absorptiometry (DXA, HOLOGIC, USA). Daily leisure activity of subjects was measured through a Baecke (Baecke et al. 1982) questionnaire.

\section{Data analysis}

Perfusion data was sampled at $8 \mathrm{~Hz}$. Baseline values of $\mathrm{CVC}$ were obtained by averaging $3 \mathrm{~min}$ of perfusion data at baseline. Vasoconstriction measures were obtained by averaging 3 min during local cooling or after administration of noradrenalin. Data for local cooling alone were normalized to baseline; total vasoconstriction response (local cooling + NA) was normalized to baseline. SPSS16.0 for Mac was used for statistics. Subject characteristics were tested for differences via Student-t testing. A MANOVA was used to test for differences in $\% \Delta C V C$ among age and gender groups. Data were presented as mean \pm SEM unless stated otherwise. Statistical significance level was set at $P<0.05$.

\section{Results}

Elderly subjects differed significantly from young adult subjects in BMI, baseline mean arterial pressure (MAP) and mean skin temperature $(P<0.05)$ (Table 1$)$. Since no significant gender differences were evident, data of both males and females were pooled. Daily leisure activity did not differ significantly between both age groups. Because BMI, baseline MAP, and mean skin temperature showed no significant relation to vasoconstriction measures and leisure activity was equal over age groups, we assumed that observed effects were mainly related to age. Due to technical malfunction during iontophoresis, testing on $n=3$ young adults and $n=1$ elderly was aborted.

To test the effectiveness of the bretylium treatment, whole body rapid cooling was applied. This resulted in a decrease of perfusion units (PU) at control sites, but not at bretylium-treated sites for both age groups: (young control
$-73 \pm 4 \%$; young bretylium $-8 \pm 6 \%$; elderly control $-65 \pm 4 \%$; elderly bretylium $-5 \% \pm 3 \%$ ).

At bretylium-treated sites baseline CVC values did not differ significantly between age groups. Control sites also showed no age effect except for the ventral hand (young adults $0.66 \pm 0.12 \mathrm{PU} / \mathrm{mmHg}$ vs. elderly $0.31 \pm 0.04$ $\mathrm{PU} / \mathrm{mmHg} ; P<0.02)$.

Non-noradrenalin treated skin sites

Bretylium-treated sites at the ventral forearm and dorsal side of the hand (non-glabrous skin) showed a significantly smaller percentage change in CVC due to local cooling than non-treated sites (see Table 3). At the glabrous skin site (ventral hand) vasoconstriction to local cooling at BR+ sites was not significantly different than vasoconstriction at $\mathrm{BR}$ - sites, indicating that local mechanisms dominated. At bretylium-treated sites no significant age effect to local cooling was found. At control sites (BR-), only the ventral forearm showed reduced vasoconstriction in elderly $(P<0.05)$.

\section{Noradrenalin-treated skin sites}

After iontophoresis of a supra-physiological dose of noradrenalin perfusion decreased significantly at all measurement sites (Table 2). The change in CVC was significantly smaller in elderly as compared with young adults at the bretylium-treated sites of the ventral forearm $(P<0.01)$, indicating a reduced response to noradrenalin in elderly. However, at the ventral and dorsal sides of the hand no significant age effect was found. The effect of noradrenalin at control $(\mathrm{BR}-)$ compared with bretylium-treated $(\mathrm{BR}+)$ sites was not significantly different at the hand sites, but lower at the ventral forearm $(P<0.05)$.

\section{Discussion}

This study explored age effects in vasoconstriction during local cooling at three different sites of the skin. For the first time, the dorsal and ventral sides of the hand were measured, in addition to the ventral forearm that is traditionally studied. The primary findings of this study are

1. There was no significant age effect on vasoconstrictor response to local cooling at both glabrous and non-glabrous skin of the hand.

2. In contrast to the results from the ventral forearm skin, elderly did not show a blunted response to noradrenalin during local cooling at hand skin sites. This indicates that at hand skin the noradrenergic mechanism of vasoconstriction is maintained with age. 
Table 3 Change in skin perfusion due to local cooling (in \% from baseline) at the ventral forearm, dorsal hand, and ventral hand

$B R-$ Control site (no bretylium), $B R+$ bretylium-treated skin,

$N A$ - before local administration of noradrenalin, $N A+$ after local administration of noradrenalin

* Significant difference in vasoconstriction compared with $\mathrm{BR}+$ $\mathrm{NA}-(P<0.05)$

\# Significant difference in vasoconstriction compared with $\mathrm{BR}+\mathrm{NA}+(P<0.05)$

\begin{tabular}{lllll}
\hline $\begin{array}{l}\text { Vasoconstriction to } \\
\text { local cooling and } \\
\text { noradrenalin }\end{array}$ & BR+ NA- & BR-NA- & BR+ NA+ & BR-NA+ \\
\hline $\begin{array}{l}\text { Ventral forearm } \\
\text { Young adults }\end{array}$ & $-22 \pm 7$ & $-46 \pm 5^{*}$ & $-76 \pm 3^{*}$ & $-57 \pm 6^{\#}$ \\
Elderly & $-14 \pm 4$ & $-33 \pm 3^{*}$ & $-60 \pm 5^{*}$ & $-45 \pm 4^{\#}$ \\
Age effect & N.S. & $P<0.05$ & $P<0.05$ & N.S. $(P<0.07)$ \\
Dorsal hand & $-32 \pm 5$ & $-49 \pm 6^{*}$ & $-74 \pm 4^{*}$ & $-71 \pm 4$ \\
Young adults & $-27 \pm 5$ & $-45 \pm 5^{*}$ & $-72 \pm 4^{*}$ & $-65 \pm 3$ \\
Elderly & N.S. & N.S. & N.S. & N.S. \\
Age effect & $-35 \pm 14$ & $-49 \pm 6$ & $-80 \pm 7^{*}$ & $-63 \pm 3$ \\
Ventral hand & $-37 \pm 11$ & $-59 \pm 5$ & $-70 \pm 11^{*}$ & $-67 \pm 5$ \\
$\quad$ Young adults & N.S. & N.S. & N.S. & N.S. \\
Elderly & & & & \\
Age effect & & & & \\
\hline
\end{tabular}

\section{Ventral forearm}

Studies by Thompson et al. (Thompson et al. 2005a; Thompson-Torgerson et al. 2007b) have shown that at the ventral forearm vasoconstrictor response to local cooling is not different between young adults and elderly. Yet the mechanisms that mediate vasoconstriction are different. Elderly have a decreased noradrenergic vasoconstriction response, which is compensated by increased vasoconstriction through local mechanisms. In the present study, however, we observed a blunted vasoconstriction in elderly to local cooling at the control skin site $(P<0.05)$. On the other hand, our observation that the neural (noradrenergic) response is reduced in elderly was in line with earlier studies that also indicate reduced sensitivity to noradrenalin at the ventral forearm (Thompson et al. 2005a, b). This was strengthened by the result that the vasoconstriction response of noradrenalin at bretylium-treated skin (BR+ $\mathrm{NA}+$ ), was significantly smaller in the elderly.

At ventral forearm skin that had sympathetic blockade $(\mathrm{BR}+)$, we observed no age effect in vasoconstriction to local cooling. This indicates that the elderly did not show increased vasoconstriction through local mechanisms.

\section{Dorsal hand}

The dorsal hand (non-glabrous skin) showed no age effect of vasoconstriction to local cooling at both bretyliumtreated and control sites. Even the application of exogenous noradrenalin did not result in an age effect. Both in young adults and elderly, the bretylium-treated skin sites showed a significantly smaller vasoconstrictor effect to local cooling alone than the control site. This indicates that at the dorsal hand, similar to the ventral forearm, vasoconstriction during early phase local cooling was obtained through noradrenergic and non-adrenergic pathways. In combination with the absence of an age effect during local cooling alone at the control site, this indicates that aging per se does not alter noradrenergic sensitivity. This was strengthened by the results that no age effect is found after administration of noradrenalin $(\mathrm{BR}+\mathrm{NA}+$ ).

\section{Ventral hand}

The ventral hand, like the dorsal hand, showed no age effect of vasoconstriction either to local cooling or to vasoconstriction after administration of noradrenalin. Glabrous skin consists of capillaries and arterio-venous anastomoses (AVA). Non-glabrous skin only has capillaries. These AVAs, which are solely innervated by sympathetic adrenergic nerves, are capable of shunting blood directly from the arteriole to the venous bed, thereby bypassing the capillaries and drastically reducing cutaneous blood flow (Kellogg 2006). Suprisingly, despite greater sympathetic innervation at glabrous skin sites (Defrin et al. 2009) no significant difference in vasoconstriction was observed between the $\mathrm{BR}+$ and $\mathrm{BR}-$ site during local cooling. This indicates that at the ventral hand, vasoconstriction by local mechanisms was able to compensate for lack of vasoconstriction by noradrenergic mechanisms. An interesting parallel may be drawn with another study by Wilson et al. (2005), who found that glabrous skin with sympathetic blockade was still able to autoregulate flow during blood pressure variations, whereas non-glabrous skin lost its capability of autoregulation.

From a functional perspective of thermoregulation, the ventral side of the hand, as compared with the dorsal side and the ventral forearm, is most adapted as a heat exchanger through the abundance of AVAs (DeGroot and Kenney 2007; Grahn et al. 2009; Van Someren 2007) and 
high sensitivity to temperature changes (Defrin et al. 2009). Various studies underscore the importance of glabrous skin areas (Gilbert et al. 1999; Grahn and Craig Heller 2004; Krauchi and Wirz-Justice 1994). Therefore, maintaining the functionality as heat exchanger of these skin areas is more important than, for instance, at the less exposed forearm. Analogous to the beneficial effects of physical exercise on vascular reactivity (Lenasi and Strucl 2004), naturally occurring exposure to cold of the hands might keep the skin of elderly "fit" to respond to daily changes in environmental temperatures.

\section{Limitations}

Other studies on local regulation of skin perfusion cited in this article in general used $34^{\circ} \mathrm{C}$ for baseline whole body mean skin temperature and local skin temperature. Although we used bretylium to avoid effects of systemic sympathetic tone, this may still have influenced results on non-treated sites. Furthermore, relatively fit and healthy elderly were selected. Despite age in years was indicative of senescence, the biological age could have been much younger. Therefore, subject selection based on biological age would make sense. Yet, the difficulty remains how to define the biological age. Since the majority of elderly in western societies are taking drugs that affect blood pressure $(69.6 \%$ of aged over 65 years in the Netherlands (CBS 2009)), it may be interesting to study whether these elderly, whose biological age might better reflect their age in years, do show a greater effect of age in vascular responses. Furthermore, the delivery of drugs through iontophoresis might induce a vasodilator response, by stimulating c-fibers, which has to be overcome before actual vasoconstriction is measured (Drummond and Lipnicki 1999). In this study, no age effect was found for the small iontophoretic vasodilation at any of the measured locations. Furthermore, despite differences in protocols, vasoconstriction values found in our study matched that of Thompson et al. (Thompson et al. 2005a) with respect to vasoconstrictor response to noradrenalin imposed on local cooling.

\section{Summary}

In summary, there was no significant age effect on vasoconstrictor response to local cooling at both glabrous and nonglabrous skin of the hand. This is in line with the results from earlier studies on the ventral forearm. Contrary to earlier studies, elderly did not show a blunted response to noradrenalin during local cooling. This indicates that at hand skin sites the noradrenergic (neural) mechanism of vasoconstriction is maintained with age.

\section{Conclusion}

In contrast to the results from literature covering ventral forearm studies, our study on hand skin sites shows that upon cooling both local (non-neural) and noradrenergic (neural) mechanisms of vasoconstriction are maintained in the elderly.

Acknowledgments This study was supported by SenterNovem, The Netherlands.

Conflict of interest statement None

Open Access This article is distributed under the terms of the Creative Commons Attribution Noncommercial License which permits any noncommercial use, distribution, and reproduction in any medium, provided the original author(s) and source are credited.

\section{References}

Alvarez GE, Zhao K, Kosiba WA, Johnson JM (2006) Relative roles of local and reflex components in cutaneous vasoconstriction during skin cooling in humans. J Appl Physiol 100:2083-2088

Baecke JA, Burema J, Frijters JE (1982) A short questionnaire for the measurement of habitual physical activity in epidemiological studies. Am J Clin Nutr 36:936-942

Bergersen TK, Eriksen M, Walloe L (1997) Local constriction of arteriovenous anastomoses in the cooled finger. Am J Physiol 273:R880-886

Carmeli E, Patish H, Coleman R (2003) The aging hand. J Gerontol A Biol Sci Med Sci 58:146-152

CBS (2009) Zelfgerapporteerde medische consumptie, gezondheid en leefstijl. Centraal Bureau voor de Statistiek

Charkoudian N (2003) Skin blood flow in adult human thermoregulation: how it works, when it does not, and why. Mayo Clin Proc 78:603-612

Choi JK, Miki K, Sagawa S, Shiraki K (1997) Evaluation of mean skin temperature formulas by infrared thermography. Int J Biometeorol 41:68-75

Defrin R, Petrini L, Arendt-Nielsen L (2009) Spatial summation of thermal sensations depends on skin type and skin sensitivity. Exp Brain Res

DeGroot DW, Kenney WL (2007) Impaired defense of core temperature in aged humans during mild cold stress. Am J Physiol Regul Integr Comp Physiol 292:R103-108

Donadio V, Nolano M, Provitera V, Stancanelli A, Lullo F, Liguori R, Santoro L (2006) Skin sympathetic adrenergic innervation: an immunofluorescence confocal study. Ann Neurol 59:376-381

Drummond PD, Lipnicki DM (1999) Noradrenaline provokes axon reflex hyperaemia in the skin of the human forearm. J Auton Nerv Syst 77:39-44

Ekenvall L, Lindblad LE, Norbeck O, Etzell BM (1988) alpha-Adrenoceptors and cold-induced vasoconstriction in human finger skin. Am J Physiol 255:H1000-1003

Gilbert SS, van den Heuvel CJ, Kennaway DJ, Dawson D (1999) Peripheral heat loss: a predictor of the hypothermic response to melatonin administration in young and older women. Physiol Behav 66:365-370

Gorgas K, Bock P, Tischendorf F, Curri SB (1977) The fine structure of human digital arterio-venous anastomoses (Hoyer-Grosser's organs). Anat Embryol (Berl) 150:269-289

Grahn D, Craig Heller H (2004) Heat Transfer in Humans: Lessons from Large Hibernators. In: Barnes BM, Carey HV (eds) Life in 
the cold: evolution, mechanisms, adaptation, and application. Biological papers of the University of Alaska

Grahn DA, Dillon JL, Heller HC (2009) Heat loss through the glabrous skin surfaces of heavily insulated, heat-stressed individuals. J Biomech Eng 131:071005

Hodges GJ, Zhao K, Kosiba WA, Johnson JM (2006) The involvement of nitric oxide in the cutaneous vasoconstrictor response to local cooling in humans. J Physiol 574:849-857

Hodges GJ, Traeger JA 3rd, Tang T, Kosiba WA, Zhao K, Johnson JM (2007) Role of sensory nerves in the cutaneous vasoconstrictor response to local cooling in humans. Am J Physiol Heart Circ Physiol 293:H784-789

Johnson JM (2007) Mechanisms of vasoconstriction with direct skin cooling in humans. Am J Physiol Heart Circ Physiol 292:H16901691

Johnson JM, Pergola PE, Liao FK, Kellogg DL Jr, Crandall CG (1995) Skin of the dorsal aspect of human hands and fingers possesses an active vasodilator system. J Appl Physiol 78:948-954

Kellogg DL Jr (2006) In vivo mechanisms of cutaneous vasodilation and vasoconstriction in humans during thermoregulatory challenges. J Appl Physiol 100:1709-1718

Kellogg DL Jr, Johnson JM, Kosiba WA (1989) Selective abolition of adrenergic vasoconstrictor responses in skin by local iontophoresis of bretylium. Am J Physiol 257:H1599-1606

Krauchi K, Wirz-Justice A (1994) Circadian rhythm of heat production, heart rate, and skin and core temperature under unmasking conditions in men. Am J Physiol 267:R819-829

Krogstad AL, Elam M, Karlsson T, Wallin BG (1995) Arteriovenous anastomoses and the thermoregulatory shift between cutaneous vasoconstrictor and vasodilator reflexes. J Auton Nerv Syst $53: 215-222$

Lenasi H, Strucl M (2004) Effect of regular physical training on cutaneous microvascular reactivity. Med Sci Sports Exerc 36:606-612

Lindblad LE, Ekenvall L, Klingstedt C (1990) Neural regulation of vascular tone and cold induced vasoconstriction in human finger skin. J Auton Nerv Syst 30:169-173

Panza JA, Epstein SE, Quyyumi AA (1991) Circadian variation in vascular tone and its relation to alpha-sympathetic vasoconstrictor activity. N Engl J Med 325:986-990
Parsons K (2003) Human Thermal Environments. Taylor \& Francis

Pergola PE, Kellogg DL Jr, Johnson JM, Kosiba WA, Solomon DE (1993) Role of sympathetic nerves in the vascular effects of local temperature in human forearm skin. Am J Physiol 265:H785-792

Thompson CS, Holowatz LA, Kenney WL (2005a) Attenuated noradrenergic sensitivity during local cooling in aged human skin. J Physiol 564:313-319

Thompson CS, Holowatz LA, Kenney WL (2005b) Cutaneous vasoconstrictor responses to norepinephrine are attenuated in older humans. Am J Physiol Regul Integr Comp Physiol 288:R11081113

Thompson-Torgerson CS, Holowatz LA, Flavahan NA, Kenney WL (2007a) Cold-induced cutaneous vasoconstriction is mediated by Rho kinase in vivo in human skin. Am J Physiol Heart Circ Physiol 292:H1700-1705

Thompson-Torgerson CS, Holowatz LA, Flavahan NA, Kenney WL (2007b) Rho kinase-mediated local cold-induced cutaneous vasoconstriction is augmented in aged human skin. Am J Physiol Heart Circ Physiol 293:H30-36

van Marken Lichtenbelt WD, Daanen HA, Wouters L, Fronczek R, Raymann RJ, Severens NM, Van Someren EJ (2006) Evaluation of wireless determination of skin temperature using iButtons. Physiol Behav 88:489-497

Van Someren EJ (2007) Thermoregulation and aging. Am J Physiol Regul Integr Comp Physiol 292:R99-102

Wilson TE, Monahan KD, Short DS, Ray CA (2004) Effect of age on cutaneous vasoconstrictor responses to norepinephrine in humans. Am J Physiol Regul Integr Comp Physiol 287:R1230 1234

Wilson TE, Zhang R, Levine BD, Crandall CG (2005) Dynamic autoregulation of cutaneous circulation: differential control in glabrous versus nonglabrous skin. Am J Physiol Heart Circ Physiol 289:H385-391

Yamazaki F, Sone R (2006) Different vascular responses in glabrous and nonglabrous skin with increasing core temperature during exercise. Eur J Appl Physiol 97:582-590 